\title{
Release of adsorbed ferulic acid in simulated gastrointestinal conditions
}

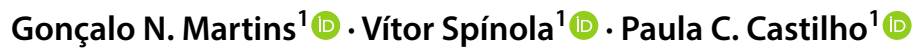

Received: 2 February 2020 / Revised: 21 March 2020 / Accepted: 25 March 2020 / Published online: 9 April 2020

(c) Springer-Verlag GmbH Germany, part of Springer Nature 2020

\begin{abstract}
Ferulic acid (FA) is a natural antioxidant with limited absorption when conjugated with biomolecules but whose free form is readily absorbed in the stomach and, to a lesser extent, in the ileum. The latter suffers from inflammation and oxidative stress, so a novel strategy for the delivery of FA in this compartment of the gastrointestinal tract was developed. Using the neutral un-functionalized resin Lewatit ${ }^{\circ}$ VP OC 1064 MD PH, under optimized conditions, a loading of $144 \mathrm{mg}$ FA/g of dry resin was obtained. By means of an in vitro simulated digestion, an average release of $32 \mathrm{mg} \mathrm{FA} / \mathrm{g}$ of dry loaded resin (recovery of 22\%) was observed in intestinal conditions. The incorporation/release of FA onto/from the resin was confirmed by ATR-FTIR spectroscopy and by HPLC-DAD. This work showed that the free form of FA can effectively be delivered in the small intestine, after immobilization in solid matrices.
\end{abstract}

Keywords Ferulic acid $\cdot$ Adsorption $\cdot$ Release $\cdot$ In vitro digestion simulation $\cdot$ Intestine

\begin{tabular}{|c|c|}
\hline \multicolumn{2}{|c|}{ Abbreviations } \\
\hline ATR-FTIR & $\begin{array}{l}\text { Attenuated total reflectance-Fourier trans- } \\
\text { form infrared }\end{array}$ \\
\hline $\mathrm{C}_{0}$ & Initial concentration \\
\hline $\mathrm{CA}$ & Caffeic acid \\
\hline $\mathrm{C}_{\mathrm{e}}$ & Concentration at equilibrium \\
\hline ChA & 5-O-Caffeoylquinic acid \\
\hline $\mathrm{C}_{\mathrm{r}}$ & Concentration of released ferulic acid \\
\hline FA & Ferulic acid \\
\hline GI & Gastrointestinal \\
\hline $\mathrm{HCA}(\mathrm{s})$ & Hydroxycinnamic acid(s) \\
\hline HPLC-DAD & $\begin{array}{l}\text { High-performance liquid chromatography } \\
\text { with diode-array detection }\end{array}$ \\
\hline Lewatit & Lewatit@ VP OC 1064 MD PH \\
\hline$m$ & Mass of resin \\
\hline $\mathrm{pCA}$ & $p$-Coumaric acid \\
\hline$q_{\mathrm{e}}$ & $\begin{array}{l}\text { Amount of compound adsorbed for unit } \\
\text { mass of adsorbent }\end{array}$ \\
\hline
\end{tabular}

Electronic supplementary material The online version of this article (https://doi.org/10.1007/s00217-020-03489-w) contains supplementary material, which is available to authorized users.

Paula C. Castilho

pcastilho@staff.uma.pt

1 CQM-Centro de Química da Madeira, Universidade da Madeira, Campus da Penteada, 9020-105 Funchal, Portugal

$\begin{array}{ll}q_{\mathrm{r}} & \begin{array}{l}\text { Amount of ferulic acid released from the } \\ \text { resin }\end{array} \\ \mathrm{SA} & \text { Sinapic acid } \\ V & \text { Volume of solution } \\ V_{\mathrm{r}} & \text { Volume of simulated medium }\end{array}$

\section{Introduction}

Ferulic acid (FA, 4-hydroxy-3-methoxycinnamic acid) is a phenolic compound, specifically a hydroxycinnamic acid. It is a potent antioxidant found in plant tissues mainly as a component of primary cell walls [1]. Among foodstuffs, cereals are the richest dietary source of FA, although it can be found in fruits, vegetables, and several beverages (e.g. coffee, beer) [2].

One of the most documented bioactivities of FA is its antioxidant capacity, resulting from the formation of a resonance-stabilized phenoxy radical structure [3, 4]. The health-beneficial effects of FA have been proposed against several acute and chronic pathologies, such as diabetes, intestinal ischemia, Alzheimer's disease, cancer, and cardiovascular diseases [4-8]. The ameliorative effects of FA in bowel diseases have been particularly studied. Administration of FA derivatives to colitis-induced rats showed positive effects, so these compounds were suggested as potential preventive or therapeutic agents for 
gastrointestinal (GI) inflammatory diseases [9, 10]. The anti-inflammatory action was attributed to the mechanism of antioxidation mediated by the inhibition of NF-kB expression and arachidonic acid metabolism. This finding was later reinforced by other authors [11], who reported that FA upregulates the expression of HO-1 (heme oxygenase 1 mRNA) and Nrf-2.

The health benefits of FA depend on its absorption, which depends on its bioaccessibility. FA is found in nature in the free form or bound to carbohydrates and other biomolecules by etherification and esterification; and depending on its form, it can be either absorbed during the digestive process or metabolized by the microflora in the cecum [12-14]. Reportedly, 25\% of FA present in foodstuffs such as tomatoes is effectively absorbed; however, the absorption of FA from cereals is very low [15]. The difference in the absorbance of FA is attributed to the presence of the free form of FA in the first case (e.g. tomatoes) and of the bound form in the latter (e.g. cereals). After the absorption of FA obtained from cereals, only 3\% (of FA and its metabolites) was detected in urine, whereas $50 \%$ was detected when the free form was administrated [16]. The free form is well absorbed in the small intestine and more extensively in the stomach $[2,17]$. In food matrices, FA is mostly covalently bonded as side chains to carbohydrate molecules such as arabinoxylans, which compromise its absorption [14, 18]. Malunga and Beta [19] isolated feruloyl-arabinoxylans from maize and wheat and submitted their compounds to a simulated gastric digestion; they found out that the gastric medium can produce feruloyl arabinofuranose but not the free form of FA.

Most FA-containing foodstuffs are not capable of appropriately promoting the interaction between FA and the small intestine walls because free FA is absorbed in the stomach and FA bound to carbohydrates will only be released and absorbed when reaching the colon. To direct FA to the small intestinal mucosa, an alternative approach can be the encapsulation of free FA in matrices that resist the low $\mathrm{pH}$ of the stomach, thus retaining the compound during the gastric phase of the digestion, but are able to release FA once the $\mathrm{pH}$ rises in the small bowel [14]. Encapsulation systems for FA based on cyclodextrins, lipidic nanoparticles, micelles, microemulsions, and electrospun fibres have been developed [20-23]. The adsorption and desorption of FA on synthetic resins [24-26] and zeolites [27] have also been explored.

Lewatit ${ }^{\circledR}$ VP OC 1064 MD PH, an FDA-approved resin for the treatment of food products (e.g. juices), is a neutral adsorbent resin and is described as a material suited for the purification/extraction of a large variety of organic compounds, both natural and synthetic, highly stable over a wide $\mathrm{pH}$ range [28]. It has the capacity to selectively adsorb hydroxycinnamic acids (HCAs) from hydrolysed complex matrices without the co-adsorption of sugars. Here, we evaluate the release of adsorbed FA from this resin when submitted to simulated GI conditions.

\section{Materials and methods}

\section{Chemicals and reagents}

All reagents and standards were of analytical reagent grade. Acetonitrile (99.9\%) was purchased from Carlo Erba (Cornaredo, Italy). $p$-Coumaric $(\geq 98 \%)$ and sinapic $(\geq 99 \%)$ acids were acquired from Fluka (Lisbon, Portugal). Lewatit ${ }^{\circledR}$ VP OC 1064 MD PH was kindly provided by LANXESS (Germany). $\alpha$-amylase (porcine pancreas, type VI-B), caffeic ( $\geq 98 \%$ ), chlorogenic (3-O-caffeoylquinic, $\geq 95 \%$ ), ferulic ( $\geq 99 \%$ ), formic ( $\geq 98 \%$ ) acids, mucin (type II; from porcine stomach), lipase (type II; from porcine pancreas), pepsin (porcine gastric mucosa) and porcine bile extract (contains glycine and taurine conjugates of hyodeoxycholic acid and other bile salts) were all purchased from Sigma-Aldrich (St. Louis, MO, USA). Other lab reagents were obtained from conventional commercial suppliers. Ultrapure water (Milli-Q Waters purification system; $18 \mathrm{M} \Omega \mathrm{cm}$ at $23{ }^{\circ} \mathrm{C}$; Millipore; Milford, MA, USA) was also used in this study.

\section{Adsorption experiments}

\section{Selection, characteristics, and preparation of the adsorbent}

The adsorbent resin Lewatit ${ }^{\circledR}$ VP OC 1064 MD PH (Lewatit) is a neutral un-functionalized crosslinked polystyrene resin with a wide range $\mathrm{pH}(0-14)$ and thermal $(-20$ to $120^{\circ} \mathrm{C}$ ) stability. The $0.44-\mathrm{mm}-0.54-\mathrm{mm}$ white, opaque, porous beads have a surface area of $800 \mathrm{~m}^{2} / \mathrm{g}$, a pore volume of $1.2 \mathrm{~cm}^{3} / \mathrm{g}$, and an average pore diameter of $5 \mathrm{~nm}-10 \mathrm{~nm}$ [28]. Preliminary data show that this resin is suitable for the adsorption of polyphenols such as HCAs. Before the experiments, the resin was preconditioned as recommended by the supplier and described elsewhere [29]. Briefly, the resin was washed consecutively with $6 \% \mathrm{HCl}$, distilled water and $4 \%$ $\mathrm{NaOH}$ until the $\mathrm{pH}$ of the cleaning water was close to that of distilled water. The water retention percentage of the resin was determined to be $64 \%$, using a moisture analyser (DBS 60-3, Kern).

\section{Optimization of the adsorption experiments}

The experimental conditions were optimized by mixing the resin with FA solutions in 2\% ethanol:water. The effect of the amount of adsorbent used (5-20 mg resin/mL solution), FA's initial concentration $(0.25-1.0 \mathrm{mg} / \mathrm{mL})$, temperature $\left(10-40{ }^{\circ} \mathrm{C}\right)$, and contact time on the efficiency of the adsorption was studied. A standard protocol, consisting of mixing 
$3 \mathrm{~mL}$ of a $0.5 \mathrm{mg} / \mathrm{mL}$ FA solution with $30 \mathrm{mg}$ of resin for $5 \mathrm{~h}$, at $23{ }^{\circ} \mathrm{C}$ (room temperature), was used as initial conditions, after which each parameter was changed while keeping the remaining constant. For the study of the contact time effect, a mixture of $250 \mathrm{mg}$ of resin and $50 \mathrm{~mL}$ of a $0.5 \mathrm{mg} /$ $\mathrm{mL} F A$ solution was placed in a water bath at room temperature with magnetic stirring at $100 \mathrm{rpm}$ for $5 \mathrm{~h}$, during which $1 \mathrm{~mL}$ aliquots were withdrawn, at certain times.

All adsorption experiments were performed in triplicate, protected from light, and with head-over-heels rotation (Reax 2, Heidolph) at $100 \mathrm{rpm}$. Controls without resin were also performed. After each assay, samples were centrifuged for $20 \mathrm{~min}$ at $4000 \mathrm{rpm}$ and $10{ }^{\circ} \mathrm{C}$ and filtered with $0.45-\mu \mathrm{m}$ cellulose acetate filters (Frilabo).

After quantification of FA in solution by HPLC-DAD, the efficiency of the adsorption was determined by calculating the $q_{\mathrm{e}}$ value (mg FA/g dry resin):

$q_{\mathrm{e}}=\frac{\left(C_{0}-C_{\mathrm{e}}\right) \times V}{m}$,

where $q_{\mathrm{e}}$ is the amount of compound adsorbed for unit mass of dry adsorbent $(\mathrm{mg} / \mathrm{g}) ; C_{0}$ and $C_{\mathrm{e}}$ are the initial and equilibrium concentrations $(\mathrm{mg} / \mathrm{mL})$ of the adsorbate, respectively; $V$ is the volume of solution used $(\mathrm{mL}) ; m$ is the mass of resin used (g, dry weight).

A final adsorption assay was performed, in triplicate, in larger quantities, combining the optimized parameters: $5000 \mathrm{mg}$ resin was mixed with $1000 \mathrm{~mL}$ of a $0.5 \mathrm{mg} / \mathrm{mL}$ FA solution, for $2 \mathrm{~h}$ at $23{ }^{\circ} \mathrm{C}$, with magnetic stirring at $100 \mathrm{rpm}$. After the adsorption, the loaded resin from the three assays was washed thrice with $10 \mathrm{~mL}$ of distilled water, lyophilized, and mixed. The samples were kept in the dark at $4{ }^{\circ} \mathrm{C}$.

ATR-FTIR spectra of standard FA (powder) and unloaded and loaded resin were collected between the spectral range of 650 and $4000 / \mathrm{cm}$, with a resolution of $4 / \mathrm{cm}$ and acquiring 36 scans per spectrum.

\section{Resin selectivity}

FA was the main compound studied in this work; however, in a food matrix, several HCAs are usually present, albeit in very different amounts. Therefore, the selectivity of the resin towards the most common HCAs was evaluated by the resin's efficacy in removing each of the five compounds from a solution similar to that prepared for FA only and the experimental procedure for the adsorption studies were performed as previously stated.

To mimic a somewhat real matrix, a mixture containing FA, $p$-coumaric (pCA), caffeic (CA), sinapic (SA), and chlorogenic (5-O-caffeoylquinic acid, $\mathrm{ChA}$ ) acids was prepared. For this, $25 \mathrm{mg}$ of each was dissolved in $1000 \mu \mathrm{L}$ of ethanol, and the volume was made up to $50 \mathrm{~mL}$ with distilled water, resulting in a concentration of $0.5 \mathrm{mg} / \mathrm{mL}$ of each HCA in a $2 \%$ ethanol solution. In the experiments, $3 \mathrm{~mL}$ of this solution and $15 \mathrm{mg}$ of resin were used.

\section{HPLC-DAD analysis and FA quantification}

Quantification of FA and other HCAs (CA, ChA, pCA and SA) was performed using high-performance liquid chromatography with diode-array detection (HPLC-DAD), on a Dionex UltiMate 3000 series instrument (Thermo Scientific Inc., California) equipped with a binary pump, an autosampler, and a column compartment at $30^{\circ} \mathrm{C}$. Elutions were carried out on a Phenomenex Gemini $\mathrm{C}_{18}$ column $(5 \mu \mathrm{m}$, $250 \times 3.0 \mathrm{~mm}$ i.d.) with ultrapure water acidified with formic acid at $0.1 \%$ and acetonitrile. The DAD acquisition was done at $320 \mathrm{~nm}$. All samples and standards were filtered with $0.45-\mu \mathrm{m}$ cellulose acetate filters (Frilabo) prior to their injection. Additional information of the chromatographic analysis can be found in Online Resource 1, namely the runs' conditions and the method's validation.

\section{Release of FA in simulated digestion conditions}

Samples of loaded resin prepared according to the optimized experimental conditions were lyophilized prior to the assays and kept in the dark, at $4{ }^{\circ} \mathrm{C}$.

\section{Simulated in vitro digestion}

Briefly, $250 \mathrm{mg}$ loaded resin was sequentially incubated at $37{ }^{\circ} \mathrm{C}$ with simulated juices whose $\mathrm{pH}$ and compositions reflected those of the GI environments of the mouth $(6 \mathrm{~mL}$ of salivary juice, $\mathrm{pH} 6.8)$, the stomach $(12 \mathrm{~mL}$ of gastric juice, $\mathrm{pH} 1.30)$, and the small intestine $(12 \mathrm{~mL}$ of duodenal and $6 \mathrm{~mL}$ of bile juices, $\mathrm{pH} 8.1$ and $\mathrm{pH} 8.2$, respectively) $[30,31]$. The composition of the juices (Online Resource 2) mimics that of each of the simulated GI compartments, with site-specific salts and enzymes. The amount of sample was adjusted from the $2 \mathrm{~g}$ used by Pinto et al. [30] to $250 \mathrm{mg}$ because the resin used here is very similar to other resinate materials used in health applications, e.g. in drug delivery or as bile acid sequestrants, where the normal daily dosage in humans can range from $270 \mathrm{mg}$ to $24 \mathrm{~g}[32,33]$.

Samples were placed in 50-mL Falcon tubes, in a water bath at $37{ }^{\circ} \mathrm{C}$, in the dark, and then GI-simulated juices were added and magnetically shaken at $500 \mathrm{rpm}$. To accurately assess the release of FA in each stage of the digestion, independent experiments were made ending the incubation either in the oral, gastric, or intestinal step, in triplicate. After each digestion, samples were recovered and centrifuged. The supernatant was filtered with $0.45-\mu \mathrm{m}$ cellulose acetate filters and analysed in the HPLC-DAD for quantification; and ATR-FTIR spectra of the solid residue, consisting of, 
mainly, (un)loaded resin, were collected. A summary of the procedure is detailed in Fig. 1.

The amount of FA released from the resin, $q_{\mathrm{r}}(\mathrm{mg} / \mathrm{g})$, was calculated, after determining FA's concentration $\left(C_{\mathrm{r}}\right.$, $\mathrm{mg} / \mathrm{mL}$ ) in each stage of the in vitro-simulated digestion, by the following equation, where $V_{\mathrm{r}}$ is the volume $(\mathrm{mL})$ at each stage and $m_{\mathrm{r}}$ is the amount $(\mathrm{g})$ of loaded resin used in the assay:

$q_{\mathrm{r}}=\frac{C_{\mathrm{r}} \times V_{\mathrm{r}}}{m_{\mathrm{r}}}$.

\section{Statistical analysis}

All assays were done in triplicate and the results are given as the mean for each experiment. Data analysis was carried out by means of a one-way ANOVA with Tukey's post hoc test using SPSS for Windows, IBM SPSS Statistics 20 (SPSS, Inc., USA). A value of $p<0.05$ was considered statistically significant.

Fig. 1 Scheme of the in vitrosimulated digestion procedure

\section{Results}

\section{Adsorption experiments}

\section{Optimization of the adsorption experiments}

The results obtained during the adsorption experiments are shown in Fig. 2. The loading of FA onto the resin increased

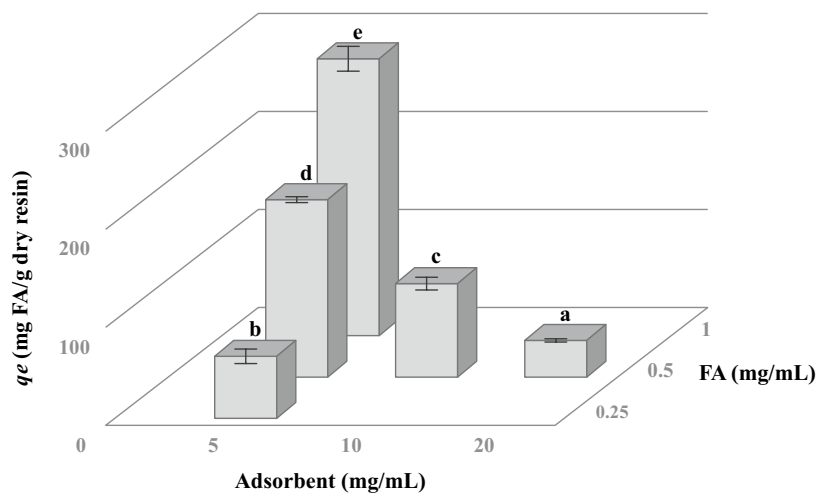

Fig. 2 Optimization of the adsorption of FA on Lewatit. Mean values not sharing the same letters are statistically different $(p<0.05)$

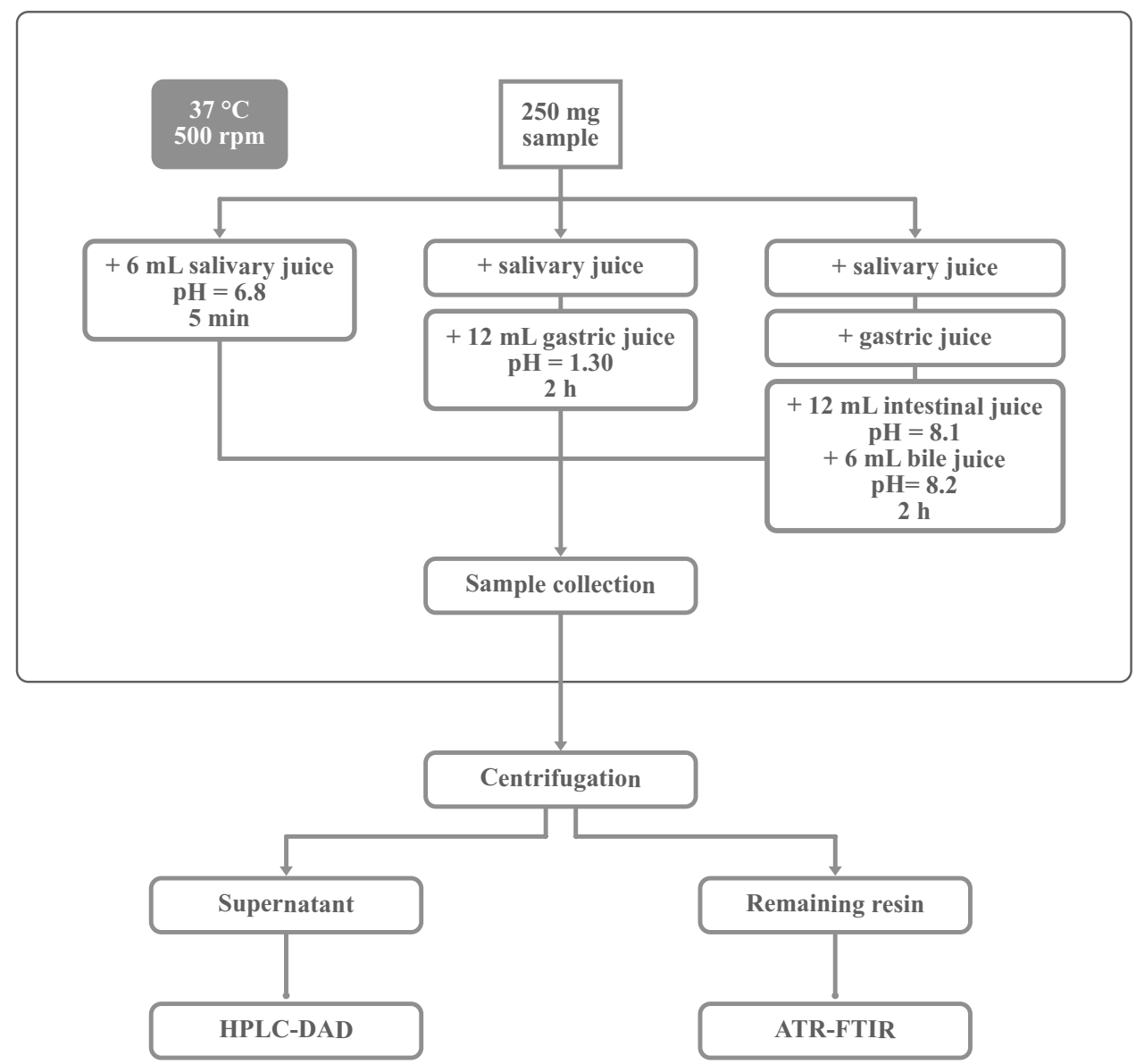


when using the lowest proportion of resin/FA solution $\left(5 \mathrm{mg} / \mathrm{mL}\right.$ ), providing a $q_{\mathrm{e}}$ of $189 \mathrm{mg} \mathrm{FA} / \mathrm{g}$ of dry Lewatit, so this ratio was used for the rest of the work. In the adsorption experiments with different initial FA concentrations, the highest loading efficiency was obtained after increasing the concentration of FA - with $1.0 \mathrm{mg} / \mathrm{mL}$ FA solutions, a $q_{\mathrm{e}}$ of $312 \mathrm{mg} / \mathrm{g}$ was registered.

There were no significant differences between the results obtained for the experiments at room temperature $\left(23^{\circ} \mathrm{C}\right)$, at $10{ }^{\circ} \mathrm{C}$ and $40{ }^{\circ} \mathrm{C}(p>0.05)$; the $q_{\mathrm{e}}$ ranged between 189 and $203 \mathrm{mg} / \mathrm{g}$ (Online Resource 3), so the following experiments were performed at room temperature.

The plot of the percentage of adsorption versus time was made to determine when the adsorption process of FA reached its equilibrium-when there are no noteworthy changes in the percentage of adsorption in time. From the experimental data, a model function was plotted. A good correlation was obtained between the experimental and calculated values $r=0.985(p=0.01)$ as shown in Fig. 3; the function was determined to have the equation: $y=52.0 \times\left(1-e^{-t / 30.7}\right)$, meaning that the system will evolve in time, as the percentage of adsorption stabilizes at $52.0 \%$, after approximately $2 \mathrm{~h}$.

The optimal conditions for the adsorption assays consisted of mixing $5 \mathrm{mg}$ resin/mL of a FA solution with a concentration of $0.5 \mathrm{mg} / \mathrm{mL}$ for $2 \mathrm{~h}$ at room temperature. This experiment was carried out with larger quantities and provided a loading of $144 \mathrm{mg} \mathrm{FA} / \mathrm{g}$ of dry resin (58\%).

\section{ATR-FTIR spectroscopy}

ATR-FTIR spectroscopy was used to confirm the loading of FA on the polystyrene resin. The unloaded and loaded polystyrene resin's spectra showed some similarities (Fig. 4), although the incorporation of FA resulted in some differences. There is the appearance of new peaks in the Lewatit + FA spectrum, at $1685 / \mathrm{cm}, 1267 / \mathrm{cm}$, and $1184 / \mathrm{cm}$, resulting from the presence of oxygen-containing functional groups of $\mathrm{FA}, \mathrm{C}=\mathrm{O}, \mathrm{C}-\mathrm{O}-\mathrm{C}$, and $\mathrm{C}-\mathrm{O}$, respectively. In addition, some peaks became more intense after the incorporation of FA into the resin, such as those at $1602 / \mathrm{cm}, 1511 /$ $\mathrm{cm}$, and $702 / \mathrm{cm}$. However, some of FA's characteristic peaks seem to be overlapped by those of the resin itself. Moreover, the free $\mathrm{OH}$ band $(3430 / \mathrm{cm})$, from the phenolic $\mathrm{OH}$ group of FA, and the two broad bands (3100-2500/cm), attributed to hydrogen-bonded (dimerized) carboxylic groups, seen in the FA spectrum later appear as a broad band around 3500/ $\mathrm{cm}$ in the Lewatit + FA's spectrum.

\section{Resin selectivity}

The resin's selectivity was studied using a mixture of the most common HCAs. ChA and CA were the least adsorbed compounds $(0 \mathrm{mg} / \mathrm{g}$ and $4 \mathrm{mg} / \mathrm{g}$, respectively) in the present conditions, while pCA, FA, and SA were the HCAs who showed the best results, with loadings of $77 \mathrm{mg} / \mathrm{g}, 109 \mathrm{mg} / \mathrm{g}$ and $179 \mathrm{mg} / \mathrm{g}$ Lewatit, respectively.

\section{Simulated digestion}

\section{Release of FA}

The complete simulated digestion provided the most extensive release of FA, with a $q_{\mathrm{r}}$ of $32 \mathrm{mg} / \mathrm{g}$, followed by the oral incubation step $(8 \mathrm{mg} / \mathrm{g})$ and by the gastric step with the lowest average release $(5 \mathrm{mg} / \mathrm{g})$. The same trend was observed
Fig. 3 Study of the effect of contact time over the adsorption

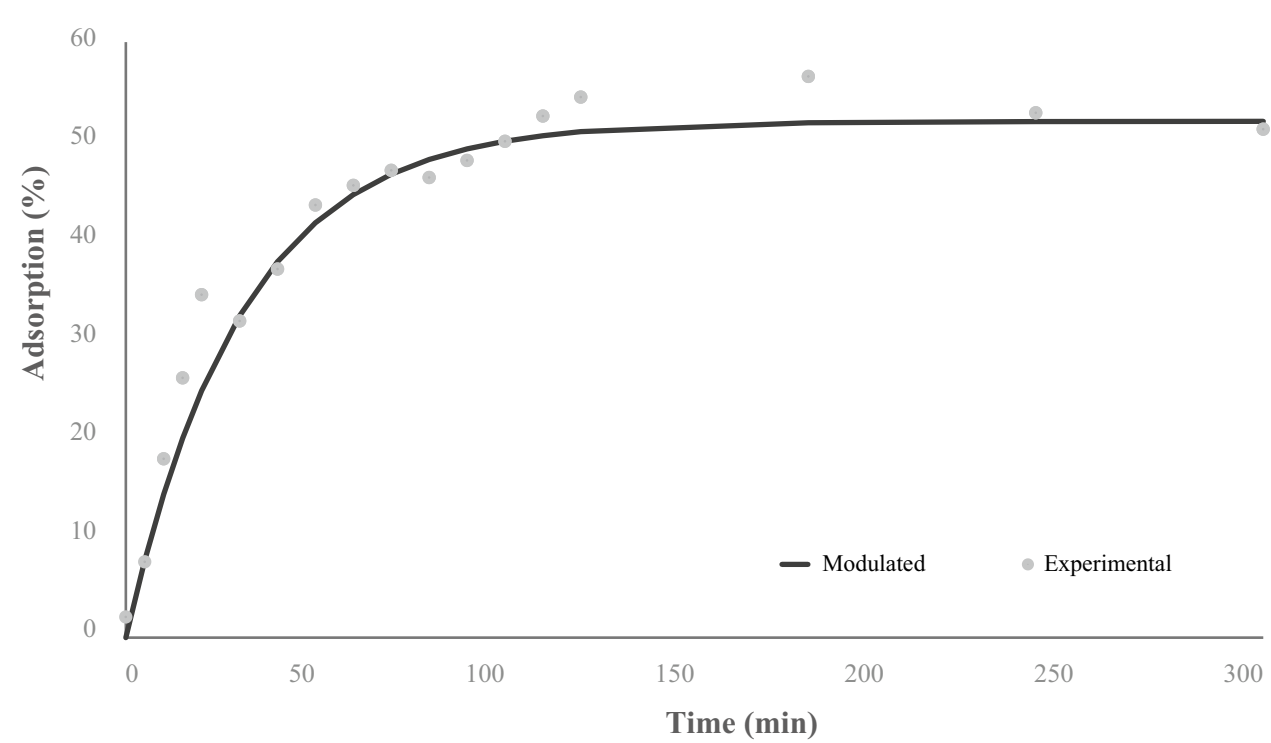


Fig. 4 ATR-FTIR spectra of FA and Lewatit, before and after the adsorption of FA by the resin

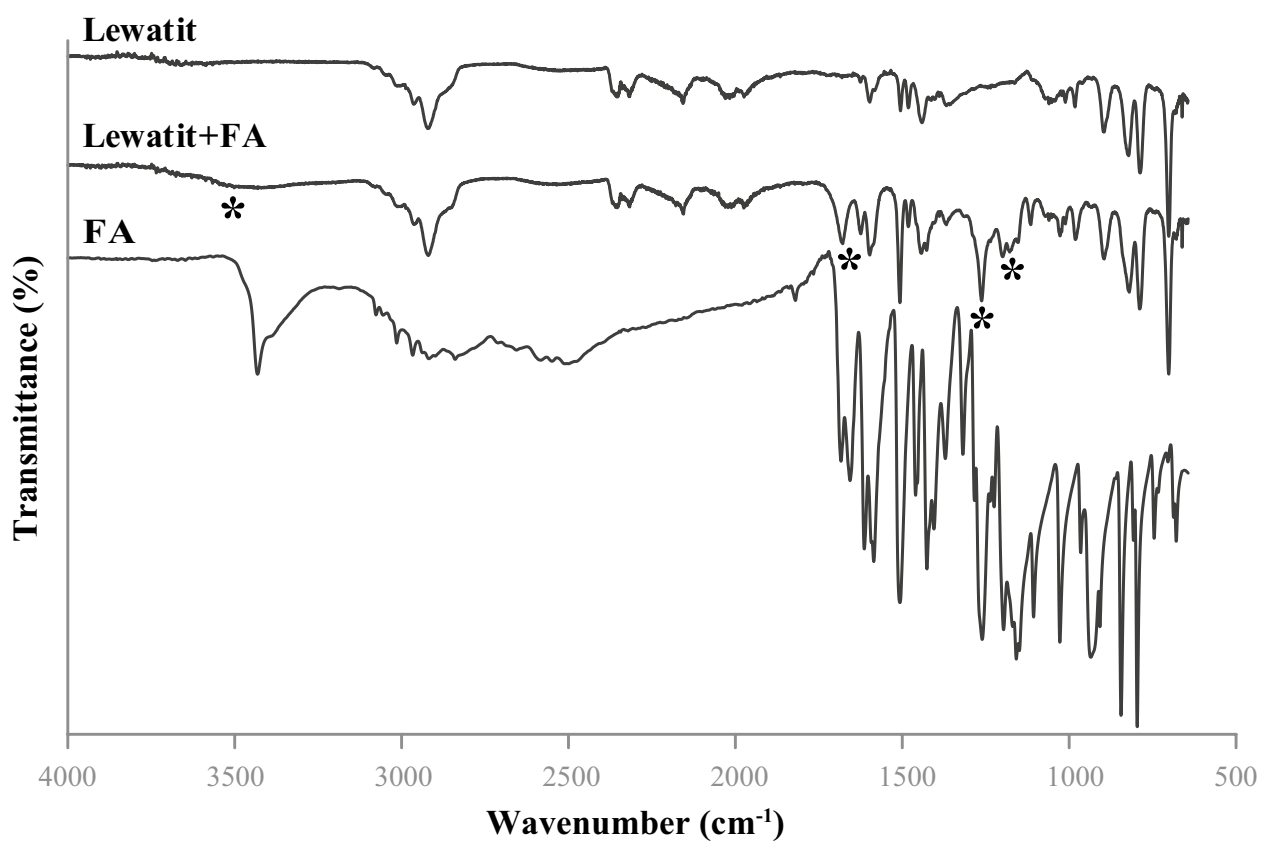

on a parallel experiment with the simulated GI juices in the absence of adjuncts and enzymes (data not shown), suggesting that $\mathrm{pH}$ and ionic strength have a greater influence in the release of FA than the activity of the enzymes present in the GI-simulated juices. No FA oxidation products were observed in the HPLC-DAD analysis.

\section{ATR-FTIR spectroscopy}

ATR-FTIR spectra of the resin were collected after each stage of the in vitro digestion simulation assays (Fig. 5). In general, all spectra still resemble that of the (un)loaded resin, after the simulation. The peaks at $1267 / \mathrm{cm}$ and $1205 / \mathrm{cm}$, from FA adsorbed in the resin, are still present
Fig. 5 ATR-FTIR spectra of Lewatit after the oral, gastric, and intestinal steps of the GI digestion simulation

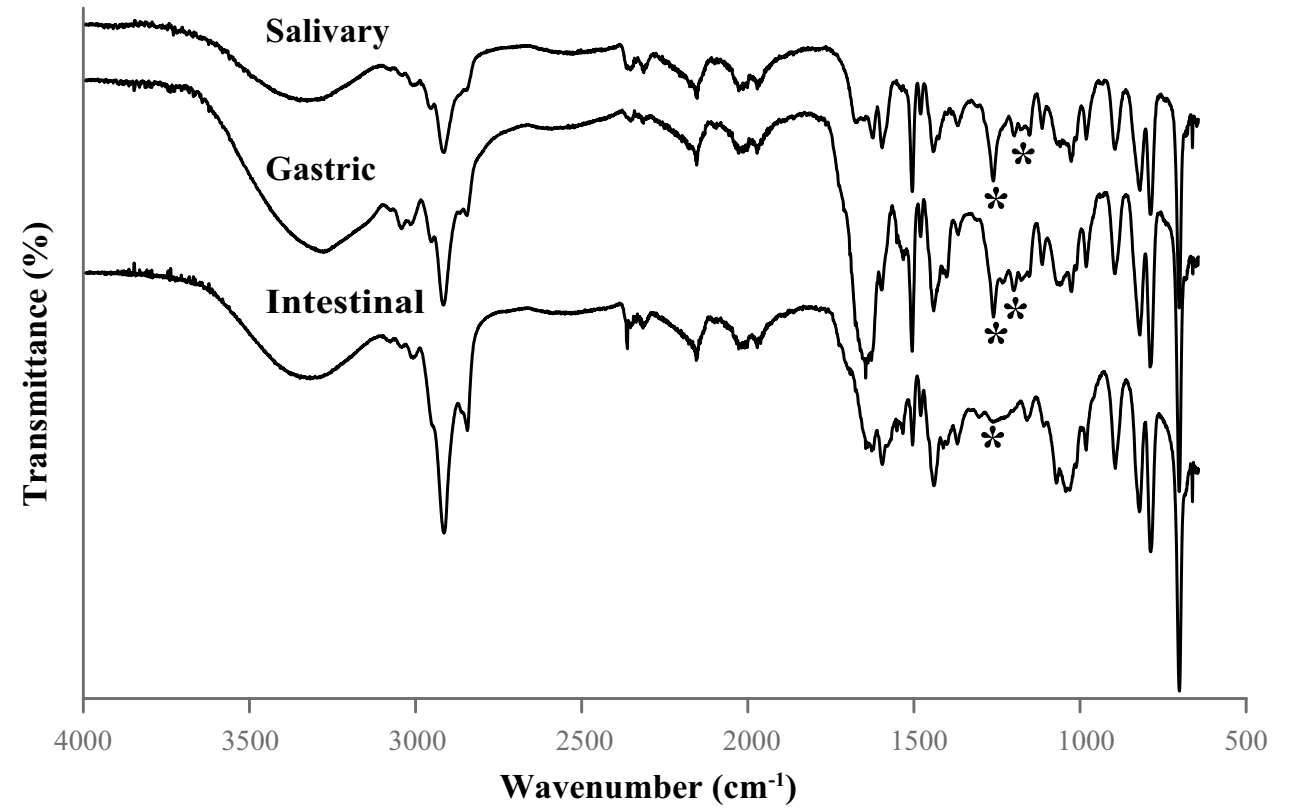


after passing the oral and gastric media but are gone after the intestinal digestion.

\section{Discussion}

\section{Adsorption experiments}

\section{Optimization of the adsorption experiments}

The adsorption of FA into the resin over different conditions was studied (Fig. 2).

When studying the resin/solution ratio, the highest loading was obtained for the $5 \mathrm{mg} / \mathrm{mL}$ proportion, so this was the chosen condition for continuing the work. DávilaGuzman et al. [24] obtained 133 mg FA/g on XAD-16, a divinylbenzene resin, using a higher proportion $(25 \mathrm{mg}$ resin/mL) and twice the initial concentration of FA. These differences are probably related to the nature (structure) of the adsorbents and their interactions with FA, suggesting FA has a higher affinity for polystyrene than divinylbenzene. In the work of Yang et al. [25], several resins were used for the adsorption of phenolic compounds and XAD16 was one of the resins with the best recovery results, suggesting that the use of Lewatit for the adsorption of FA could be advantageous.

The amount of adsorbed FA increased when the initial concentration doubled: $189 \mathrm{mg} / \mathrm{g}$ was adsorbed from a $0.5 \mathrm{mg} \mathrm{FA} / \mathrm{mL}$ solution, whereas with $1.0 \mathrm{mg} / \mathrm{mL}$ solutions, $312 \mathrm{mg} / \mathrm{g}$ was adsorbed. Despite this increase, the concentration of $0.5 \mathrm{mg} / \mathrm{mL}$ was used for the next experiments since $1.0 \mathrm{mg} / \mathrm{mL}$ is close to the limit of solubility of FA in the $2 \%$ ethanol: water mixture and stability was difficult to achieve.

Figure 3 shows the plot of the percentage of adsorption versus time. This type of curve can be divided in three sections related to (1) film diffusion, fast transport of molecules in the solution surrounding the resin-first $60 \mathrm{~min}$; (2) intraparticle diffusion, diffusion of molecules inside the adsorbent 60-120 min; (3) stabilization of the adsorption process [24]. At $2 \mathrm{~h}$, the percentage of adsorption was 51.5 , very close to the $52.0 \%$, at which the system is stable, so a separate adsorption experiment was performed with a contact time of $2 \mathrm{~h}$ and the $q_{\mathrm{e}}$ was found to be $156 \mathrm{mg} / \mathrm{g}$. Although this value was lower than $189 \mathrm{mg} / \mathrm{g}$ previously obtained, it was still higher than the $133 \mathrm{mg} / \mathrm{g}$ obtained by Dávila-Guzman et al. [24] at $2.5 \mathrm{~h}$.

\section{ATR-FTIR spectroscopy}

The overall similarities between the spectra of the unloaded and loaded resin indicate the structure of the resin does not suffer any changes after the incorporation of FA but the appearance of new peaks corresponding to those of the FA's spectrum suggest FA was effectively adsorbed into the resin. This notion is further supported by the appearance of a single sharp peak at around 3500/ $\mathrm{cm}$ instead of a broad brand, like in the spectrum of FA, suggesting the interaction between the resin and FA is not a simple deposition of FA on the resin's surface and that FA is not dimerized.

\section{Resin selectivity}

For this work, the loading of the resin Lewatit was done by adsorption of FA from $2 \%(\mathrm{~V} / \mathrm{V})$ ethanol aqueous solutions of the pure compound. However, it was hypothesized that if the resin were selective towards FA, the option of loading it from a food matrix extract would save a purification step.

Since the solution used was a mixture of five compounds (CA, ChA, FA, pCA, and SA), the results may suggest a competition for the active sites of the resin by the analytes. SA appears as the HCA with the highest affinity for the neutral polymer, probably because the hydrophobic interactions increase with its extra methyl groups. Adsorption seems to be dependent on the compounds' hydrophobicity, i.e. the higher the hydrophobic nature of the acid, the higher the adsorption yield - hydrophobic forces are the main interactions in adsorption processes on neutral non-polar resins, such as Lewatit. This order of adsorption is the same as their elution from the reverse phase chromatographic column and the reverse to their solubility in water.

In food matrices from which FA is usually obtained, SA is often present in much smaller amounts $(<10 \%$ of FA) [34]. Nevertheless, these results show that using this method in real samples would involve the simultaneous adsorption of SA by the resin.

Kammerer et al. [26] performed recovery studies of various phenolic compounds from apple pomace extract using Lewatit and observed that $\mathrm{ChA}$ was well adsorbed in acid $\mathrm{pH}$ (pH 1). This contradictory result may be explained by differences in the experimental design since an $80 \%$ methanolic aqueous solution, a different $\mathrm{pH}$, and a recirculatory packedbed system were used. In the same work, the adsorption (and desorption) of other phenolic compounds (e.g. gallic acid, catechin) and at different $\mathrm{pH}$ values are also described; however, there is no mention of FA.

Kammerer et al. [35] highlighted the importance of studying the selectivity of resins, while working on the adsorption of phenolic compounds from apple juice onto the adsorbent resin Alimentech P-495, noting that the behaviour of individual compounds towards the adsorbent when dealing with complex solutions, like those found in nature, should be assessed. The bioactivity of FA depends on the natural 
source from which it is recovered since it can be found in several forms and in the presence of different compounds (HCAs and others). It is, therefore, important to understand the selectivity of the resin towards FA while present in mixtures with other biomolecules.

\section{Simulated digestion}

\section{Release of FA}

$32 \mathrm{mg} / \mathrm{g}$ of FA released is comparable to the quantities of FA found in different foodstuffs, as these range from $0.19 \times 10^{-3} \mathrm{mg} / \mathrm{g}$ of their fresh weight in pot-grown lettuces to $33 \mathrm{mg} / \mathrm{g}$ of their fresh weight in refined corn bran [2]. Not all FA found in foods is bioaccessible, being bound to carbohydrates, but in this work, it is assumed all FA can effectively be absorbed since it is the free form that is being adsorbed and released. The present work demonstrated that this approach is a possible mean for delivering free FA in large quantities in the small intestine.

The obtained results show that the $\mathrm{pH}$ of the media influences the interactions between FA and the resin: acidic media promotes the adsorption of FA and prevents its release, whereas alkaline media causes its release from the adsorbent and hinders its adsorption. Dávila-Guzman et al. [24] noticed the adsorption of FA onto the neutral adsorbent resin XAD-16 was favoured at low $\mathrm{pH}$ and decreased in media with $\mathrm{pH}>4$, because the ionization of FA (pKa1 $=4.46 ; \mathrm{pKa} 2=8.77$ ) in neutral and basic solutions weakens the hydrophobic interactions responsible for the adsorption. Also, in the work of Geerkens et al. [36], polyphenols were recovered from mango-peel extracts using Lewatit and their adsorption was much higher at $\mathrm{pH} 1$ than at $\mathrm{pH}$ 7. In the present work, the amount of released FA during the gastric step $(\mathrm{pH}=1.30)$ is lower than the amount released in intestinal conditions $(\mathrm{pH}=8.1)$. This is probably caused by the $\mathrm{pH}$ difference of the media, i.e. the alkaline environment of the simulated intestinal juice promotes the release of FA by causing its ionization and subsequently weakening its interactions with the resin.

Adsorbent and ion-exchange resins have been used to concentrate and purify mixtures containing phenolic compounds obtained from natural sources, e.g. fruit juices or extracts. These resins are considered selective for these compounds and are used for the removal of undesired compounds, such as amino acids, that are not retained by the resin [26]. Polyphenols can, then, be recovered, usually, with alcoholic or hydro-alcoholic solutions [25, 26, 37-39]. Ethanol, for instance, is a common eluent because it is efficient, eco-friendly and non-toxic but the use of methanol is also common [40]. Since this work evaluates the release of FA in GI conditions, these solvents were not used.
When designing this experiment, the objective was the evaluation of the release of FA from the resin when the resin-FA complex was submitted to the conditions found in the GI tract, e.g. the pH shifts. Kammerer et al. [26] studied the adsorption of polyphenols from apple pomace and grape skin using Lewatit. When desorbing these compounds, two conditions were tested: one using methanol:water (30:70, V/V) and one with the same eluent but previously washing the resin with $2 \mathrm{M} \mathrm{HCl}$. Although the acidic solution was an inefficient eluent, just as the gastric juice was in this work, this pre-step was beneficial for the recovery of phenols. The acidification followed by a sudden $\mathrm{pH}$ shift effectively weakened the interactions between the compounds and the resin, promoting the release of the polyphenols. This information suggests the passage through the gastric step, in this work, is essential for a more extensive release of FA in the intestinal media.

Moreover, during a real-life digestion process there are several enzymes and other compounds present in solution. Although the enzymes and other adjuncts used in these simulations were not expected to have any activity over the Lewatit +FA formulation, since adsorption resins are materials considered inert and resistant, their inclusion was important to assess the release of FA in these complex conditions. In fact, when the full digestion simulation process was assayed, there was a change in the resins' colour, from colourless/white into yellowish-brown (Online Resource 4) - the same colour as the bile-simulated juice. This change was attributed to a potential adsorption of bile acids from the bile-simulated juice (Online Resource 2), because adsorbent and ion-exchange resins are used as bile acid sequestrants, i.e. they are administered per os for the treatment of health conditions, e.g. intractable diarrhoea, and for lowering cholesterol levels through the adsorption of bile acids [32, 41, 42]. Since it has been reported that FA has anti-cholesterolemic activity, the concomitant use of both substances could have a beneficial synergetic effect for the reduction of cholesterol levels [5].

\section{ATR-FTIR spectroscopy}

The ATR-FTIR spectra of the resin beads (Fig. 5) suggest the integrity and structure of the adsorbent were kept after being subjected to the simulated digestion media (different $\mathrm{pH}$ and enzyme activity). Additionally, the extensive release of FA during the intestinal step suggested by the HPLC-DAD results is supported by the disappearance of the peaks at $1267 / \mathrm{cm}$ and $1205 / \mathrm{cm}$ from the spectra between the gastric and intestinal steps. It was previously suggested that bile acids were adsorbed to Lewatit after the intestinal incubation step; however, the spectral analysis does not clearly reveal the peaks related to these 
compounds, probably due to an overlap with the peaks from other substances.

\section{Conclusions}

To the best of our knowledge, this is the first study of the in vitro release of FA from an adsorbent resin in simulated GI media. This work proved that free FA immobilized on a non-charged material can successfully overpass the low $\mathrm{pH}$ of the stomach and be released in the small intestine, where its action is much needed. The dietary intake of FA presents some limitations in terms of its bioaccessibility, and this study showed that using appropriate solid adsorbents for the delivery of the free compound, this problem can be potentially addressed.

\section{Availability of data and material}

The data that support the findings of this study are available from the corresponding author upon reasonable request.

Acknowledgements The authors acknowledge LANXESS, Germany, for providing the resin Lewatit@ VP OC 1064 MD PH. David Quintal is also acknowledged for the artwork. This work was part of the master's dissertation of G.N.M.

Author contributions GNM did the experimental work. VS helped with the chromatographic analyses and with the gastrointestinal digestion simulation, statistical analysis, and manuscript revision. GNM and PCC contributed for the analysis and discussion of results and writing of the manuscript. PCC coordinated the work and did the final revision of the manuscript. All authors have approved the final version of the manuscript.

Funding This study was funded by Fundação para a Ciência e a Tecnologia (CQM Project PEstOE/QUI/UI0674/2019, Portuguese Government funds, by Madeira 14-20 Program, project PROEQUIPRAMReforço do Investimento em Equipamentos e Infraestruturas Científicas na RAM (M1420-01-0145-FEDER-000008) and by ARDITI-Agência Regional para o Desenvolvimento da Investigação Tecnologia e Inovação, through the project M1420-01-0145-FEDER-000005-Centro de Química da Madeira-CQM + (Madeira 14-20 Program).

\section{Compliance with ethical standards}

Conflict of interests The authors declare no conflict of interest.

Compliance with ethics requirements No ethical issues derive from this work.

\section{References}

1. El-Seedi HR, El-Said AMA, Khalifa SAM et al (2012) Biosynthesis, natural sources, dietary intake, pharmacokinetic properties, and biological activities of hydroxycinnamic acids. J Agric Food Chem 60:10877-10895. https://doi.org/10.1021/jf301807g

2. Zhao Z, Moghadasian MH (2008) Chemistry, natural sources, dietary intake and pharmacokinetic properties of ferulic acid: a review. Food Chem 109:691-702. https://doi.org/10.1016/j.foodc hem.2008.02.039

3. Graf E (1992) Antioxidant potential of ferulic acid. Free Radic Biol Med 13:435-448. https://doi.org/10.1016/08915849(92)90184-I

4. Itagaki S, Kurokawa T, Nakata C et al (2009) In vitro and in vivo antioxidant properties of ferulic acid: a comparative study with other natural oxidation inhibitors. Food Chem 114:466-471. https ://doi.org/10.1016/j.foodchem.2008.09.073

5. Bumrungpert A, Lilitchan S, Tuntipopipat S et al (2018) Ferulic acid supplementation improves lipid profiles, oxidative stress, and inflammatory status in hyperlipidemic subjects: a randomized, double-blind, placebo-controlled clinical trial. Nutrients 10:6-13. https://doi.org/10.3390/nu10060713

6. Chowdhury S, Ghosh S, Das AK, Sil PC (2019) Ferulic acid protects hyperglycemia-induced kidney damage by regulating oxidative insult, inflammation and autophagy. Front Pharmacol 10:1-24. https://doi.org/10.3389/fphar.2019.00027

7. Ghosh S, Basak P, Dutta S et al (2017) New insights into the ameliorative effects of ferulic acid in pathophysiological conditions. Food Chem Toxicol 103:41-55. https://doi.org/10.1016/j. fct.2017.02.028

8. Mancuso C, Santangelo R (2014) Ferulic acid: pharmacological and toxicological aspects. Food Chem Toxicol 65:185-195. https ://doi.org/10.1016/j.fct.2013.12.024

9. Sadar SS, Vyawahare NS, Bodhankar SL (2016) Ferulic acid ameliorates TNBS-induced ulcerative colitis through modulation of cytokines, oxidative stress, inos, cox-2, and apoptosis in laboratory rats. EXCLI J 15:482-499. https://doi.org/10.17179/excli 2016-393

10. Dong W-G, Liu S-P, Yu B-P et al (2003) Ameliorative effects of sodium ferulate on experimental colitis and their mechanisms in rats. World J Gastroenterol 9:2533-2538. https://doi.org/10.3748/ wjg.v9.i11.2533

11. Kandhare AD, Patil A, Guru A et al (2016) Ameliorative effect of ferulic acid against acetic acid induced ulcerative colitis: role of HO-1 and Nrf2. Pharmacologia 7:114-124. https://doi. org/10.5567/pharmacologia.2016.114.124

12. Adam A, Crespy V, Levrat-Verny M-A et al (2002) The bioavailability of ferulic acid is governed primarily by the food matrix rather than its metabolism in intestine and liver in rats. J Nutr 132:1962-1968. https://doi.org/10.1093/jn/132.7.1962

13. Zhao Z, Egashira Y, Sanada H (2003) Digestion and absorption of ferulic acid sugar esters in rat gastrointestinal tract. J Agric Food Chem 51:5534-5539. https://doi.org/10.1021/jf034455u

14. Anson NM, van den Berg R, Havenaar R et al (2009) Bioavailability of ferulic acid is determined by its bioaccessibility. J Cereal Sci 49:296-300. https://doi.org/10.1016/j.jcs.2008.12.001

15. Manach C, Scalbert A, Morand C et al (2004) Polyphenols: food sources and bioavailability. Am J Clin Nutr 79:727-747. https:// doi.org/10.1093/ajen/79.5.727

16. Lafay S, Gil-Izquierdo A (2008) Bioavailability of phenolic acids. Phytochem Rev 7:301-311. https://doi.org/10.1007/s1110 1-007-9077-x

17. Zhao Z, Egashira Y, Sanada H (2004) Ferulic acid is quickly absorbed from rat stomach as the free form and then conjugated mainly in liver. J Nutr 134:3083-3088. https://doi.org/10.1093/ jn/134.11.3083

18. Donovan JL, Manach C, Faulks RM, Kroon PA (2006) Absorption and metabolism of dietary plant secondary metabolites. In: Crozier A, Clifford MN, Ashihara H (eds) Plant secondary 
metabolites-occurrence, structure and role in the human diet. Blackwell Publishing Ltd, Oxford, pp 303-351

19. Malunga LN, Beta T (2016) Isolation and identification of feruloylated arabinoxylan mono- and oligosaccharides from undigested and digested maize and wheat. Heliyon. https://doi. org/10.1016/j.heliyon.2016.e00106

20. Anselmi C, Centini M, Maggiore M et al (2008) Non-covalent inclusion of ferulic acid with $\alpha$-cyclodextrin improves photo-stability and delivery: NMR and modeling studies. J Pharm Biomed Anal 46:645-652. https://doi.org/10.1016/j.jpba.2007.11.037

21. Carlotti ME, Sapino S, Ugazio E et al (2008) Photostability of ferulic acid and its antioxidant activity against linoleic acid peroxidation. J Dispers Sci Technol 29:629-640. https://doi. org/10.1080/01932690701757766

22. Aceituno-Medina M, Mendoza S, Rodríguez BA et al (2015) Improved antioxidant capacity of quercetin and ferulic acid during in-vitro digestion through encapsulation within foodgrade electrospun fibers. J Funct Foods 12:332-341. https://doi. org/10.1016/j.jff.2014.11.028

23. Yu D-G, Yang J-M, Branford-White C et al (2010) Third generation solid dispersions of ferulic acid in electrospun composite nanofibers. Int J Pharm 400:158-164. https://doi.org/10.1016/j. ijpharm.2010.08.010

24. Dávila-Guzman NE, Cerino-Córdova FJ, Diaz-Flores PE et al (2012) Equilibrium and kinetic studies of ferulic acid adsorption by amberlite XAD-16. Chem Eng J 183:112-116. https://doi. org/10.1016/j.cej.2011.12.037

25. Yang Q, Zhao M, Lin L (2016) Adsorption and desorption characteristics of Adlay bran free phenolics on macroporous resins. Food Chem 194:900-907. https://doi.org/10.1016/j.foodc hem.2015.08.070

26. Kammerer J, Schweizer C, Carle R, Kammerer DR (2011) Recovery and fractionation of major apple and grape polyphenols from model solutions and crude plant extracts using ion exchange and adsorbent resins. Int J Food Sci Technol 46:1755-1767. https:// doi.org/10.1111/j.1365-2621.2011.02681.x

27. Simon V, Thuret A, Candy L et al (2015) Recovery of hydroxycinnamic acids from renewable resources by adsorption on zeolites. Chem Eng J 280:748-754. https://doi.org/10.1016/j. cej.2015.06.009

28. LANXESS (2011) Product information Lewatit ${ }^{\circledR}$ VP OC 1064 MD PH. https://www.lenntech.com/Data-sheets/Lewatit-VP-OC1064-MD-PH-L.pdf

29. Conidi C, Rodriguez-Lopez AD, Garcia-Castello EM, Cassano A (2015) Purification of artichoke polyphenols by using membrane filtration and polymeric resins. Sep Purif Technol 144:153-161. https://doi.org/10.1016/j.seppur.2015.02.025

30. Pinto J, Spínola V, Llorent-Martínez EJ et al (2017) Polyphenolic profile and antioxidant activities of Madeiran elderberry (Sambucus lanceolata) as affected by simulated in vitro digestion. Food Res Int 100(3):404-410. https://doi.org/10.1016/j.foodr es.2017.03.044

31. Flores FP, Singh RK, Kerr WL et al (2014) Total phenolics content and antioxidant capacities of microencapsulated blueberry anthocyanins during in vitro digestion. Food Chem 153:272-278. https://doi.org/10.1016/j.foodchem.2013.12.063

32. Egawa H, Yorifuji T, Sumazaki R et al (2002) Intractable diarrhea after liver transplantation for Byler's disease: successful treatment with bile adsorptive resin. Liver Transpl 8:714-716. https://doi. org/10.1053/jlts.2002.34384

33. Guo X, Chang R, Hussain MA (2009) Ion-exchange resins as drug delivery carriers. J Pharm Sci 98:3886-3902. https://doi. org/10.1002/jps.21706

34. Shahidi F, Chandrasekara A (2015) The use of antioxidants in the preservation of cereals and low-moisture foods. In: Shadini F (ed) Handbook of antioxidants for food preservation. Woodhead Publishing, Cambridge, pp 413-432

35. Kammerer DR, Saleh ZS, Carle R, Stanley RA (2007) Adsorptive recovery of phenolic compounds from apple juice. Eur Food Res Technol 224:605-613. https://doi.org/10.1007/s0021 7-006-0346-5

36. Geerkens $\mathrm{CH}$, Matejka AE, Schweiggert RM et al (2015) Optimization of polyphenol recovery from mango peel extracts by assessing food-grade adsorbent and ion exchange resins and adsorption parameters using a D-optimal design. Eur Food Res Technol 241:627-636. https://doi.org/10.1007/s00217-015-2489-8

37. Kammerer D, Gajdos Kljusuric J, Carle R, Schieber A (2005) Recovery of anthocyanins from grape pomace extracts (Vitis vinifera L. cv. Cabernet Mitos) using a polymeric adsorber resin. Eur Food Res Technol 220:431-437. https://doi.org/10.1007/s0021 7-004-1078-z

38. Chang X-L, Wang D, Chen B-Y et al (2012) Adsorption and desorption properties of macroporous resins for anthocyanins from the calyx extract of Roselle (Hibiscus sabdariffa L.). J Agric Food Chem 60:2368-2376. https://doi.org/10.1021/jf205311v

39. Erfurt H, Schuld R, Stürtz M et al. (2014) Antioxidant composition

40. Casas MP, Soto ML, Díaz-Reinoso B et al (2017) Purification of polyphenol extracts from natural sources-adsorption and membrane technologies. In: Cuevas-Valenzuela J, Vergara-Salinas JR, Pérez-Correa JR (eds) Advances in technologies for producing food-relevant polyphenols. CRC Press, Taylor \& Francis, Boca Raton, pp 221-259

41. Dhal PK, Huval CC, Holmes-Farley SR (2006) Polymeric sequestrants as nonabsorbed human therapeutics. In: Chorghade MS (ed) Drug discovery and development drug discovery, vol 1. Wiley, Hoboken, pp 383-404

42. Charlton-Menys V, Durrington PN (2008) Human cholesterol metabolism and therapeutic molecules. Exp Physiol 93:27-42. https://doi.org/10.1113/expphysiol.2006.035147

Publisher's Note Springer Nature remains neutral with regard to jurisdictional claims in published maps and institutional affiliations. 